\title{
2,6-Disubstituted benzothiazoles, analogues of the aromatic core of D-luciferin: synthesis and evaluation of the affinity for Photinus pyralis luciferase
}

\author{
Giuseppe Meroni, ${ }^{\text {a Paolo Ciana, }}$, Clara Meda, ${ }^{\mathrm{b}}$ Adriana Maggi, ${ }^{\mathrm{b}}$ and Enzo Santaniello ${ }^{\mathrm{a} *}$ \\ ${ }^{a}$ Dipartimento di Medicina, Chirurgia e Odontoiatria and Centro Interdipartimentale di Ricerca \\ di Imaging Molecolare e Cellulare(IMAGO), Polo Universitario S. Paolo, University of Milan, \\ via A. di Rudinì, 8- 20142 Milano, Italy \\ ${ }^{b}$ Center of Excellence on Neurodegenerative Diseases, Department of Pharmacological \\ Sciences, University of Milan, Via Balzaretti 9, 20133 Milan, Italy \\ E-mail: enzo.santaniello@unimi.it
}

\begin{abstract}
A few 2,6-disubstituted benzothiazoles have been prepared as reference compounds or starting material for the preparation of derivatives containing positron emitting fluorine in the aromatic ring. Their affinity for Photinus pyralis luciferase has been evaluated and values of $\mathrm{IC}_{50}(8.8$ $45.2 \mu \mathrm{M})$ suggest that they are competitive inhibitors of the enzyme.
\end{abstract}

Keywords: Luciferase, D-luciferin, 2,6-disubstituted benzothiazoles

\section{Introduction}

The luciferase from the North American firefly Photinus pyralis (PpyLuc) catalyzes the conversion of D-luciferin [(S)-2-(6'-hydroxy-2'-benzothiazolyl)thiazoline-4-carboxylic acid] to oxyluciferin in the presence of ATP, $\mathrm{Mg}^{2+}$, and oxygen with production of a yellow-green light characterized by a broad emission spectrum and a peak at $560 \mathrm{~nm}$ (Figure 1). ${ }^{1}$<smiles>O=C(O)[C@H]1CSC(c2nc3ccc(O)cc3s2)=N1</smiles>

Figure 1. Luciferase-catalyzed production of bioluminescence. 
PpyLuc is a well characterized enzyme that finds a large number of biotechnological applications $^{2}$ and has been used, for example, as an indicator of cell proliferation, gene delivery or gene expression in cell culture and in living animals as a transgenic marker. ${ }^{3}$ PpyLuc is at present the preferred enzyme for in vivo optical imaging of small animals, ${ }^{4}$ a useful modality of molecular imaging that presents the limit of light absorption and scattering by organs or the high dose of the reporter probe required for a sufficient emission. ${ }^{5}$ Furthermore, it is not certain to what degree the high contrast images obtained from the luciferin/luciferase bioluminescence are the result of selective substrate conversion or might be mainly dependent on substrate distribution. This could be better approached by other imaging modalities, such as single photon emission computed tomography (SPECT) and positron emission tomography (PET) that use radionuclides for imaging of reporter genes. ${ }^{6}$ In this respect, only two examples of radioactive isotopomers of D-luciferin (1a) are available, i. e. $6^{\prime}$ - $\left[{ }^{11} \mathrm{C}\right.$-methyl]-D-luciferin $\mathbf{1 b}^{7}$ and $\mathbf{7}^{\prime}$ $\left[{ }^{123} \mathrm{I}\right]$ iodo-D-luciferin $\mathbf{1 c}{ }^{8}$ However, $\mathbf{1 b}$ and $\mathbf{1 c}$ were unable to locate the tumor and showed poor cell uptake. ${ }^{7,9}$

We have recently undertaken a project aimed to prepare compounds related to D-luciferin labeled with positron emitting fluorine $\left({ }^{18} \mathrm{~F}\right)$ for the in vivo imaging of a transgenic mouse that expresses a luciferase reporter gene under the control of activated estrogen receptors. ${ }^{10}$ Initially, we evaluated the possibility of introducing ${ }^{18} \mathrm{~F}$ into the benzothiazole moiety of D-luciferin (1a) or 6'-O-methyl luciferin 1d that is a well known inhibitor of PpyLuc $\left(\mathrm{IC}_{50} 1 \mu \mathrm{M}\right) .{ }^{11,12}$ However, due to the instability of the thiazoline moiety of 1a or 1d, chemical manipulations of these compounds were excluded. ${ }^{13}$ We next considered to introduce ${ }^{18} \mathrm{~F}$ into benzothiazoles corresponding to the aromatic core of compounds 1a or 1d and 2,6-disubstituted benzothiazoles 2a were selected as starting material for the preparation of compounds $\mathbf{1 e .}$

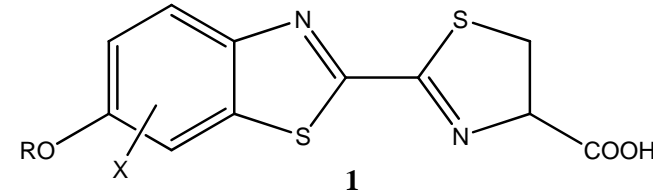
a. $\mathrm{R}=\mathrm{X}=\mathrm{H}$
c. $\mathrm{R}=\mathrm{H}, \mathrm{X}=\mathrm{7}^{\prime}-{ }^{123} \mathrm{I}$
b. $\mathrm{R}={ }^{11} \mathrm{CH}_{3}, \mathrm{X}=\mathrm{H}$
d. $\mathrm{R}=\mathrm{CH}_{3}, \mathrm{X}=\mathrm{H}$ e. $\mathrm{R}=\mathrm{H}, \mathrm{CH}_{3} ; \mathrm{X}={ }^{18} \mathrm{~F}, \mathrm{CH}_{2}{ }^{18} \mathrm{~F}$

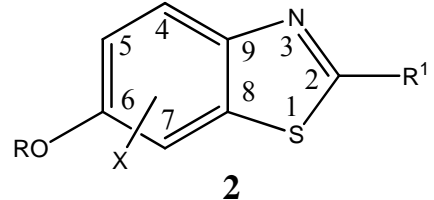

a. $\mathrm{R}=\mathrm{H}, \mathrm{CH}_{3} ; \mathrm{X}={ }^{18} \mathrm{~F}, \mathrm{CH}_{2}{ }^{18} \mathrm{~F} ; \mathrm{R}^{1}=\mathrm{CN}, \mathrm{COOH}, \mathrm{CONH}_{2}$

b. $\mathrm{R}=\mathrm{H}, \mathrm{CH}_{3} ; \mathrm{X}=\mathrm{H} ; \mathrm{R}^{1}=\mathrm{H}, \mathrm{CN}$ c. $\mathrm{R}$ and $\mathrm{R}^{1}$ various; $\mathrm{X}=\mathrm{H}$ d. $\mathrm{R}=\mathrm{H}, \mathrm{CH}_{3} ; \mathrm{X}=\mathrm{H} ; \mathrm{R}^{1}=\mathrm{CO}-\mathrm{NH}-\left(\mathrm{CH}_{2}\right)_{\mathrm{n}}{ }^{18} \mathrm{~F}$

Figure 2. Structure of D-luciferin derivatives 1a-e and 2-substituted-6-hydroxybenzothiazole analogues 2a-d.

Furthermore, compounds such as 2a could be used themselves as tracers, provided that they could show affinity for Ppyluc. We relied on early kinetic studies showing that 2,6-disubstituted benzothiazoles $\mathbf{2 b}$ are competitive inhibitors of luciferase at $\mathrm{pH} 7.7, \mathrm{~K}_{\mathrm{i}}$ ranging from 25 to $58 \mu \mathrm{M} .{ }^{11}$ Moreover, in a recent paper other benzothiazoles 2c have been examined as possible inhibitors of luciferase within a high-throughput screening (HTS) of a library of 70,000 small 
molecules. Among these compounds, a series of benzothiazole analogues showed an activity approaching an $\mathrm{IC}_{50} 0.1 \mu \mathrm{M} .{ }^{14}$ Based on this encouraging premise, we have prepared a few model compounds structurally related to compounds $2 \mathrm{a}(\mathrm{X}=\mathrm{H})$ and have evaluated their in vitro affinity for PpyLuc.

\section{Results and Discussion}

For our initial studies, we have selected 2-substituted-6-hydroxy and 6-methoxybenzothiazoles (compounds 3a-h, Figure 3) that could be prepared from nitriles 3a and 3e. The synthesis of 2cyano-6-methoxybenzothiazole $3 \mathbf{e}$ has been fully described, ${ }^{15-18}$ but we started from the commercially available compound. The nitrile $3 \mathbf{e}$ can be transformed into the 6-hydroxy analogue 3a carrying out the demethylation by fusion with pyridinium hydrochloride (Py. $\mathrm{HCl})$ at $200{ }^{\circ} \mathrm{C} .{ }^{15}$

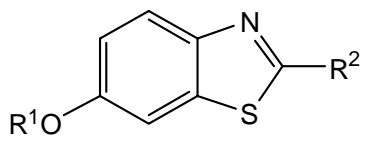

3
a. $\mathrm{R}^{1}=\mathrm{H}, \mathrm{R}^{2}=\mathrm{CN}$
e. $\mathrm{R}^{1}=\mathrm{CH}_{3}, \mathrm{R}^{2}=\mathrm{CN}$
b. $\mathrm{R}^{1}=\mathrm{H}, \mathrm{R}^{2}=\mathrm{CONH}_{2}$
f. $\mathrm{R}^{1}=\mathrm{CH}_{3}, \mathrm{R}^{2}=\mathrm{CONH}_{2}$
c. $\mathrm{R}^{1}=\mathrm{H}, \mathrm{R}^{2}=\mathrm{COOH}$
g. $\mathrm{R}^{1}=\mathrm{CH}_{3}, \mathrm{R}^{2}=\mathrm{COOH}$
d. $\mathrm{R}^{1}=\mathrm{H}, \mathrm{R}^{2}=\mathrm{C}(=\mathrm{NH}) \mathrm{OCH}_{3}$
h. $\mathrm{R}^{1}=\mathrm{CH}_{3}, \mathrm{R}^{2}=\mathrm{C}(=\mathrm{NH}) \mathrm{OCH}_{3}$

Figure 3. Structure of 6-hydroxybenzothiazole derivatives 3a-h.

This method is still the most efficient for the preparation of 2-cyano-6-hydroxybenzothiazole 3a, because the nitrile function remains intact under these conditions. A few attempts to prepare 3a from 3e with other reagents were much less efficient than Py.HCl. ${ }^{19}$ The overall preparation of compounds 3a-h is described in Scheme 1. Basic hydrolysis of the nitrile 3a to the amide $\mathbf{3 b}$ could not be controlled and this product was obtained in mixture with variable amounts of the acid 3c. However, the 6-hydroxy acid 3c is stable only for a few days as powder and in solution decarboxylates to 6-hydroxybenzothiazole 4 with a reported half-life of 31 hours. $^{20}$ We have verified the instability of the acid $3 \mathbf{c}$ in aqueous solutions at room temperature and consequently the values of $\mathrm{IC}_{50}$ were not easily reproducible. The amide $\mathbf{3 b}$ could also be prepared by a biocatalytic approach, using a specific enzyme that could catalyze the hydrolysis of a nitrile. The superfamily of nitrilases includes nitrilases and nitrile hydrolases and offers this opportunity. ${ }^{21}$ The properly named nitrilase (EC 3.5.5.1) catalyzes the hydrolysis of a nitrile to the corresponding carboxylic acid and ammonia, whereas nitrile hydrolase (EC 4.2.1.84) transforms a nitrile into an amide. ${ }^{22}$ Only nitrilases are commercially available, but occasional 
formation of amide in nitrilase-catalyzed hydolysis of nitriles has been observed. ${ }^{23}$ This partial hydrolysis may depend on the structure of the nitrile, as in the case reported for a nitrilasecatalyzed hydrolysis of a $\beta$-hydroxynitrile. ${ }^{24}$ We have used the commercially available nitrilase from Arabidopsis thaliana and carried out the reaction in a 10\% DMSO aqueous solution of the nitrile 3a. In our case, a quantitative hydrolysis to the required amide $3 \mathbf{b}$ was achieved with no formation of the corresponding acid 3c or product of its decarboxylation (compound 4). The same enzymatic reaction could not be repeated on the nitrile $\mathbf{3 e}$, only for the high insolubility of the substrate in the reaction media.
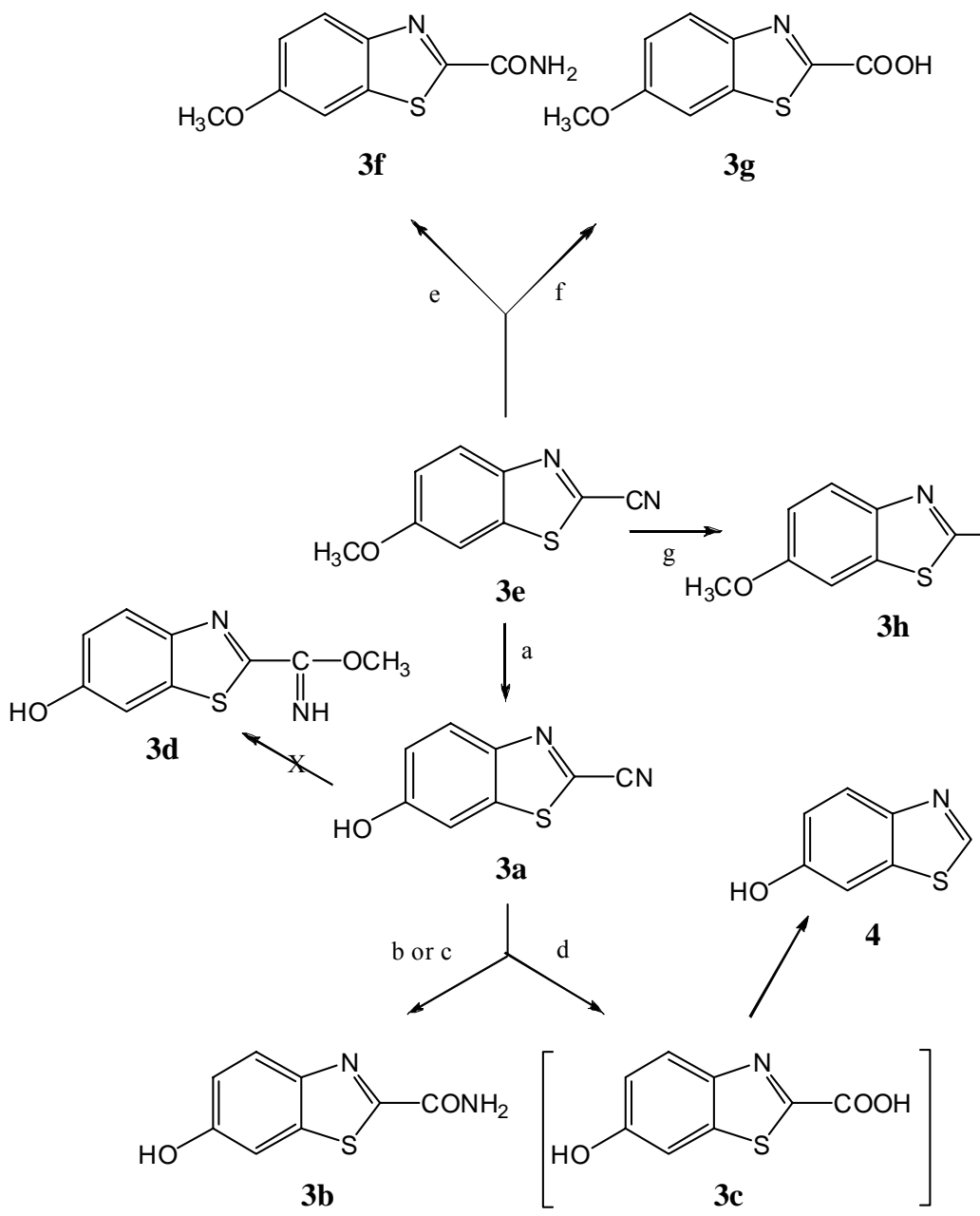

Scheme 1. Synthesis of compounds 3a-d and 3f-h from nitrile 3e. Reagents and conditions: (a) PyHCl, $200^{\circ} \mathrm{C}, 1.5 \mathrm{~h}, 70 \%$; (b) $\mathrm{NaOH} / \mathrm{THF}$, r.t., $1 \mathrm{~h}, 65 \%$; (c) nitrilase from Arabidopsis thaliana, $\mathrm{H}_{2} \mathrm{O} / \mathrm{DMSO}$ (9:1), r.t., 2 h, 98\%; (d) $\mathrm{NaOH} / \mathrm{THF}$, r.t., 3 h; (e) $\mathrm{NaOH} / \mathrm{THF}$, r.t., 1 h, $70 \%$; (f) $\mathrm{NaOH} / \mathrm{THF}$, r. t., 3 h, $98 \%$; (g) $\mathrm{MeOH} / \mathrm{NaOH}$, r.t., 3 h, $98 \%$.

For the preparation of the 6-methoxy derivatives, the basic hydrolysis of the nitrile $3 \mathbf{e}$ proceeded as described for nitrile 3a. In fact, the amide $\mathbf{3 f}$ was prepared in mixture with variable 
amounts of the acid 3g, that was, in turn, quantitatively obtained by a complete basic hydrolysis. We have also prepared the 6-methoxy imidate $3 \mathbf{h}$ from the nitrile $\mathbf{3 e}$, by a modification of a published procedure. ${ }^{25}$ Under the same conditions, the imidate $3 \mathbf{d}$ could not be prepared, confirming the result obtained by Amess et al. ${ }^{25}$ The bioluminescent assay was carried out using a recombinant PpyLuc and results are expressed as $\mathrm{IC}_{50}$ values (Table 1).

Table 1. $\mathrm{IC}_{50}$ values of 2-substituted-6-hydroxy and 6-methoxybenzothiazoles (compounds 3ah) ${ }^{\mathrm{a}}$

\begin{tabular}{cc}
\hline Substrate & $\mathrm{IC}_{50}{ }^{\mathrm{b}}$ \\
\hline 3a & 8.8 \\
3b & 45.2 \\
3e & 14.7 \\
3f & 13.0 \\
3g & 308.0 \\
3h & 16.4 \\
\hline
\end{tabular}

${ }^{a}$ Compound $3 \mathbf{c}$ is unstable in solution and did not afford reproducible results. Compound $\mathbf{3 d}$ could not be prepared from 3a under the same reaction condition that afforded the imidate $\mathbf{3 h}$ from $3 \mathbf{e}$

${ }^{\mathrm{b}} \mathrm{IC}_{50}$ refers to concentration $(\mu \mathrm{M})$ of the compound in a competition assay that causes $50 \%$ of inhibition of PpyLuc-catalyzed bioluminescence at $\mathrm{pH} 7.8$

Comparing the $\mathrm{IC}_{50}$ values of 6-hydroxybenzothiazole derivatives $3 \mathbf{a}$ and $\mathbf{3 b}$, it can be observed that substitution of the 2-cyano with an amide group leads to a slight decrease of affinity $\left(\mathrm{IC}_{50}\right.$ from 8.8 to $\left.45.2 \mu \mathrm{M}\right)$. In the 6-methoxybenzothiazole series, the presence of the methoxy group at the position 6 does not significantly affect the affinity of the 2-cyano derivatives $3 \mathbf{a}$ and $\mathbf{3 e}\left(\mathrm{IC}_{50} 8.8\right.$ and $14.7 \mu \mathrm{M}$ for nitrile $3 \mathbf{a}$ and $\mathbf{3 e}$, respectively). Furthermore, the 6-methoxy amide $3 \mathrm{f}$ shows an $\mathrm{IC}_{50}$ value nearly identical to that of the corresponding 6methoxynitrile 3e, in contrast with the difference observed between 3a and 3b. The 6-methoxy imidate $\mathbf{3 h}$ is characterized by an $\mathrm{IC}_{50}$ value similar to $\mathbf{3 e}$ and $\mathbf{3 f}$. The acid $\mathbf{3 g}$ was prepared with a view to improving the limited solubility that all the benzothiazole derivatives prepared by us exhibited in the in vitro assay. However, this acid has revealed to be a poor substrate $\left(\mathrm{IC}_{50} 308.0\right.$ $\mu \mathrm{M})$ for PpyLuc. A possible explanation of this result involves the recognition of the substrate by the enzyme that can be disfavored by the presence of a negatively charged group at position 2 . This can interfere with some amino acid residue present in the part of the active site where the compound 3g should be located. 


\section{Conclusions}

Results from our study show that benzothiazoles 3a, 3e, 3f, and 3h present an interesting affinity for PpyLuc (IC50 values 8.8-16.4 $\mu \mathrm{M}$ ), comparable to that of other benzothiazoles previously reported. ${ }^{11,14}$ It is reasonable to assume that these small-sized compounds interact in a nonspecific manner with different binding sites of the large enzymatic pocket of PpyLuc. This view of enzyme-substrate interaction has previously been proposed also to explain the magnitude of the competitive inhibition shown by other benzothiazoles ${ }^{11,14}$ and several structurally diverse

small molecules. $^{26-29}$ In any event, we have described preliminary observations about the affinity of PpyLuc for 2,6-disubstituted benzothiazole derivatives that can be considered as reference compounds or starting material for the preparation of derivatives containing positron emitting fluorine in the aromatic ring. We are currently investigating the introduction of fluorine or fluorine-containing groups in the benzothiazole nucleus of compounds 3a-h in order to obtain benzothiazoles $\mathbf{2 a}$ or $\mathbf{2 d}$, as potential tracers of luciferase reporter gene.

\section{Experimental Section}

General Procedures. Melting points were recorded on a Stuart Scientific SMP3 instrument and are uncorrected. IR spectra were recorded as $\mathrm{KBr}$ pellets on a Jasco FT-IR 300E spectrophotometer (Jasco Ltd., Tokyo, Japan). ${ }^{1} \mathrm{H}$ NMR spectra were recorded in DMSO- $\mathrm{d}_{6}$ solutions at $303 \mathrm{~K}$ on a Bruker AM-500 spectrometer equipped with an Aspect 3000 computer, a process control and an array processor. The ${ }^{1} \mathrm{H}$ - chemical shifts are reported in parts per million, using as reference the signal for residual solvent protons. Mass spectra were recorded on a Finnigan LCQ-Deca (Termoquest) in ESI positive-ion mode (KV 5.00, $\left.225{ }^{\circ} \mathrm{C}, 15 \mathrm{~V}\right)$. The progress of all reactions and column chromatography were monitored by TLC using Silica Gel $60 \mathrm{~F}_{254}$ precoated plates with a fluorescent indicator (Merck). Purification of products by chromatography was performed using silica gel 60 (230-400 mesh, Merck). All reagents were obtained from commercial sources and used without further purification. Nitrilase from Arabidopsis thaliana $(0.26 \mathrm{U} / \mathrm{mg})$ was purchased from Fluka. The nitrile 3a was prepared from nitrile $3 \mathbf{e}$ in $70 \%$ yield according to the literature method. ${ }^{15}$ All products were crystallized from methanol/water.

Enzymatic assay. The luciferase assay was carried out in 96 multiwell plates using $100 \mathrm{pg}$ recombinant luciferase (Quantilum, Promega, Madison W.I., U.S.A.). The enzyme was dissolved in a luciferine buffer $\left[\left(\mathrm{MgCO}_{3}\right)_{4} \mathrm{Mg}(\mathrm{OH})_{2} * 5 \mathrm{H}_{2} \mathrm{O}, 1 \mathrm{mM}\right.$, Tricine $(20 \mathrm{mM})$, EDTA $(0,1 \mathrm{mM})$, $\mathrm{MgSO}_{4} * 7 \mathrm{H}_{2} \mathrm{O}(2,5 \mathrm{mM})$, DTT $(33 \mathrm{mM})$, ATP $(530 \mathrm{mM}), \mathrm{pH} 7.8$ ] D-luciferin potassium salt (Promega, Madison, WI U.S.A.) was added at the final concentration of $30 \mu \mathrm{M}$ in the presence of increasing concentrations of the synthetic compounds to be tested $(10 \mathrm{nM}, 30 \mathrm{nM}, 100 \mathrm{nM}$, $300 \mathrm{nM}, 1 \mu \mathrm{M}, 3 \mu \mathrm{M}, 10 \mu \mathrm{M}, 30 \mu \mathrm{M}, 100 \mu \mathrm{M}, 300 \mu \mathrm{M}, 1 \mathrm{mM}, 10 \mathrm{mM})$. The compounds were 
solubilized in $0,1 \mathrm{M}$ phosphate buffer $\mathrm{pH} 7.2$ with $1 \% \mathrm{v} / \mathrm{v}$ DMSO. The reaction occurred at $37^{\circ} \mathrm{C}$ for $5 \mathrm{~min}$, then the quantitative analysis of the luminescence was carried out for $10 \mathrm{sec}$ using the Veritas Microplate Luminometer (Turner Biosystems, Sunnyvale, CA U.S.A.). The curve of luciferin activity was generated using 1:3 dilutions of luciferin (at concentrations from $10 \mathrm{nM}$ to $1 \mathrm{mM})$. All reactions were carried out in quadruplicate and each experiment was repeated in triplicate. All reagents were from Sigma-Aldrich (Steinheim, Germany). Half maximal inhibitory concentration $\left(\mathrm{IC}_{50}\right)$ was calculated by means of the Program PRISM5 (GraphPad Software Inc., CA U.S.A.) using Sigmoidal dose-response (variable slope) equation.

\section{General procedure of the hydrolysis of nitriles $3 a$ and $3 \mathbf{e}$.}

To a stirred solution of $3 \mathbf{a}$ or $3 \mathbf{e}(500 \mathrm{mg})$ in $15 \mathrm{~mL}$ of tetrahydrofurane, $3 \mathrm{~mL}$ of $\mathrm{NaOH} 1 \mathrm{~N}$ were added. The reaction was stirred at room temperature for $1 \mathrm{~h}$ to afford a mixture of the corresponding amide (3b or $\mathbf{3 f}$ ) and acid (3c or $\mathbf{3 g}$ ). The complete hydrolysis of nitriles to the acids was achieved stirring for $3 \mathrm{~h}$ at room temperature. At the end of the reaction, a solution of $1 \mathrm{~N} \mathrm{HCl}$ was added and the mixture extracted two times with ethyl acetate. The isolation of amides $\mathbf{3 b}$ and $\mathbf{3 f}$ required an additional step, consisting in the treatment of the ethyl acetate solution of the amide/acid mixture with a $10 \% \mathrm{NaHCO}_{3}$ solution to remove the sodium salt of the acid 3c or 3g. The organic phase was dried with sodium sulfate and evaporated.

6-Hydroxybenzothiazole-2-carboxyamide (3b). Yellow-brown solid (358 mg, 65\%); mp 168$170{ }^{\circ} \mathrm{C} \mathrm{dec}$; IR (KBr): $v_{\max } 3168,1656,1602,1556,1456,1230 \mathrm{~cm}^{-1} ;{ }^{1} \mathrm{H}-\mathrm{NMR}: \delta 7.05$ (dd, $1 \mathrm{H}$, 4-H, J $14 \mathrm{~Hz}, 3.5 \mathrm{~Hz}), 7.41$ (d, 1H, 7-H, J 3.5Hz), 7.90 (m, 2H, 5-H and CONH), 8.32 (bs, 1H, $\mathrm{CONH}), 10.18$ (bs, 1H, 6-OH); MS: (m/z , relative intensity) $194\left(\mathrm{M}^{+}, 100 \%\right), 151\left(\mathrm{M}^{+}-44\right.$, 86\%)]. Anal. Calcd. for $\mathrm{C}_{8} \mathrm{H}_{6} \mathrm{~N}_{2} \mathrm{O}_{2} \mathrm{~S}$ : C, 49.48; H, 3.09; N, 14.43. Found: C, 49.55; H, 3.14; N, 14.37.

6-Methoxybenzothiazole-2-carboxyamide (3f). Brown solid (383 mg, 70\%); mp 248-250 ${ }^{\circ} \mathrm{C}$ dec; IR (KBr): $v_{\max } 3256,1661,1604,1500,1226 \mathrm{~cm}^{-1}$; ${ }^{1} \mathrm{H}-\mathrm{NMR}: \delta 3.85$ (s, 3H, 6-OCH $), 7.20$ (d, 1H, 4-H, J 8.7 Hz), 7.75 (s, 1H, 7-H), 7.98 (d, 1H, 5-H, J 8.7 Hz), [7.95 (bs, 1H) and 8.35 (bs, $1 \mathrm{H}), \mathrm{CONH}_{2}$; $\mathrm{MS}:\left(\mathrm{m} / \mathrm{z}\right.$, relative intensity) $207\left(\mathrm{M}^{+}-1,10 \%\right), 165$ (30), 151 (100). Anal. Calcd. for $\mathrm{C}_{9} \mathrm{H}_{8} \mathrm{~N}_{2} \mathrm{O}_{2} \mathrm{~S}: \mathrm{C}, 51.92 ; \mathrm{H}, 3.85 ; \mathrm{N}, 13.46$. Found:C,52.09; $\mathrm{H}, 3.93 ; \mathrm{N}, 13.40$.

6-Methoxybenzothiazole-2-carboxylic acid (3g). Yellow-brown solid (538 mg, 98\%); mp $>300{ }^{\circ} \mathrm{C}$ dec; IR (KBr): $v_{\max } 3359-2971,1602,1440,1388,1267 \mathrm{~cm}^{-1}$;. ${ }^{1} \mathrm{H}-\mathrm{NMR}: \delta 3.80$ (s, 3H, 6- $\left.\mathrm{OCH}_{3}\right), 7.12$ (dd, 1H, 4-H, J 8.7Hz, $\left.2.0 \mathrm{~Hz}\right), 7.72$ (d, 1H, 7-H, J 2.0 Hz), 7.95 (dd, 1H, 5-H, J $8.7 \mathrm{~Hz}, 2 \mathrm{~Hz}), 9.18$ (s, 1H, COOH); MS: (m/z , relative intensity) $208\left(\mathrm{M}^{+}-1,100 \%\right), 165(45)$, 150 (67). Anal. Calcd. for $\mathrm{C}_{9} \mathrm{H}_{7} \mathrm{NO}_{3} \mathrm{~S}: \mathrm{C}, 51.67 ; \mathrm{H}, 3.35 ; \mathrm{N}, 6.70$. Found: C, 51.75; H, 3.40; N, 6.75 .

Nitrilase-catalyzed hydrolysis of 2-cyano-6-hydroxybenzothizole (3a): enzymatic preparation of 6-hydroxybenzothiazole-2-carboxyamide (3b)

To a stirred solution of nitrile 3a $(120 \mathrm{mg}, 0.68 \mathrm{mmol})$ in $5 \mathrm{~mL}$ of a water/dimethyl sulfoxyde solution (9/1) at room temperature, nitrilase from Arabidopsis Thaliana (10 mg) was added and 
the reaction was stirred for $2 \mathrm{~h}$ and only the amide $3 \mathbf{b}$ was revealed by TLC (dichloromethane/methanol 95:5). The mixture was filtered, diluted with water $(3 \mathrm{~mL})$ and extracted with ethyl acetate. The organic phase was dried over sodium sulfate and the product was recovered in 98\% yield as a yellow-brown solid. All chemico-physical characteristics were in agreement with the structure of the amide $\mathbf{3 b}$.

\section{Methyl 6-methoxybenzothiazole-2-carboxyimidate (3h)}

To a stirred solution of the nitrile $3 \mathbf{e}(500 \mathrm{mg}, 2.62 \mathrm{mmol})$ in methanol $(15 \mathrm{~mL}), 1 \mathrm{~N} \mathrm{NaOH}$ $(3 \mathrm{~mL})$ was added and the reaction was stirred at room temperature $(3 \mathrm{~h})$. The reaction was diluted with water $(10 \mathrm{~mL})$ and extracted with ethyl acetate. The organic phase was dried (sodium sulfate) and the product recovered as a white solid (570 mg, 98\%). All chemico-physical characteristics were as described for $3 \mathbf{h} .^{25}$

\section{Acknowledgements}

This work was financially supported by the European Project EMIL (European Molecular Imaging Laboratories, LSHC-Ct-2004-503569) entitled "Molecular Imaging for Early Detection of Tumors and Monitoring of Treatment". Part of the work has constituted the experimental thesis of Dr. Elisa Galli (Laurea in Chimica e Tecnologia Farmaceutiche, Facoltà di Farmacia, Università di Milano).

\section{References and Notes}

1. White, E. H.; Rapaport, E.; Seliger, H. H.; Hopkins, T. A. Bioorg. Chem. 1971, 1, 92.

2. Roda, A.; Pasini, P.; Mirasoli, M.; Michelini, E.; Guardigli, M. Trends Biotechnol. 2004, 22, 295.

3. Contag, C. H.; Bachmann, M. H. Ann. Rev. Biomed. Eng. 2002, 4, 235.

4. (a) Söling A.; Rainov N.G. Expert Opin. Biol. Ther. 2003, 3, 1163. (b) Lüker, G. D.; Lüker, K. E. J. Nucl. Med. 2008, 49, 1.

5. For luciferase-mediated gene imaging a dose of $125 \mathrm{mg} / \mathrm{Kg}$ of D-luciferin is required: $\mathrm{Wu}, \mathrm{J}$. C.; Sundaresan, G.; Iyer, M.; Gambhir, S. S. Mol. Ther. 2001, 4, 297.

6. (a) Rahmim, A.; Zaidi, H. Nucl. Med. Commun. 2008, 29, 193. (b) Iyer, M.; Sato, M.; Johnson, M.; Gambhir, S.S.; Wu, L. Curr. Gene Ther. 2005, 5,607. (c) Kjaer, A. Adv Exp Med Biol. 2006,587,277. (d) Massoud, T. F.; Gambhir, S. S. Genes Develop. 2003, 17, 545.

7. Wang, J.-Q.; Pollok, K.E.; Cai, S.; Stantz, K. M.; Hutchins, G. D.; Zheng, Q.-H. Bioorg. Med. Chem. Lett. 2006. 16, 331.

8. Lee, S.-Y.; Choe, Y.S.; Lee, K.-H.; Lee, J.; Choi, Y.; Kim, B.-T. Bioorg. Med. Chem Lett. 2004, 14, 1161. 
9. Lee, K. H.; Byun, S.; Paik, J. Y.; Song, S. H.; Choe, Y. S.; Kim, B. T. Nucl. Med. Commun. 2003, 24, 1003.

10. Ciana, P.; Raviscioni, M.; Mussi, P.; Vegeto, E.; Que, I.; Parker, M. G.; Lowik, C.; Maggi, A. Nature Medicine 2003, 9, 82.

11. Denburg, J. L.; Lee, R. T.; McElroy, W. D. Archiv. Biochem. Biophys. 1969, 134, 381.

12. Barros, M. P.; Bechara, E. J. H. Free Rad. Biol. Med. 1998, 24, 767.

13. For instance, we have attempted to prepare 6'-O-methyl luciferin 1d from D-luciferin (1a). The methylation of compound 1a under a variety of experimental conditions afforded mixture of products, due to the instability of D-luciferin itself and also a few attempts of radiosynthesis failed. Starting from the methyl ester of D-luciferin, the corresponding $\left[{ }^{11} \mathrm{C}\right]$ methyl ether has later been prepared by reaction with $\left[{ }^{11} \mathrm{C}\right]-\mathrm{CH}_{3} \mathrm{OTf}$. ${ }^{7}$

14. Auld, D. S.; Southall, N. T.; Jadhav, A.; Johnson, R. L.; Diller, D. J.; Simeonov, A.; Austin, C. P.; Inglese, J. J. Med. Chem. 2008, 51, 2372.

15. White, E.; McCapra, F.; Field, G. F. J. Am. Chem. Soc. 1963, 85, 337.

16. Seto, S.; Ogura, K.; Nishiyama, Y. Bull. Chem. Soc. Jpn. 1963, 36, 332.

17. Toya, Y.; Takagi, M.; Nakata, H.; Suzuki, N.; Isobe, M.; Goto, T. Bull. Chem. Soc. Jpn. 1992, 65, 392.

18. Suzuki, N.; Nomoto, T.; Toya, Y.; Kanamori, N.; Yoda, B.; Saeki, A. Biosci. Biotech. Biochem. 1993, 57, 1561.

19. We have also tried other reagents for the demethylation step such as $\mathrm{BBr}_{3}$ or trimethylsilyl iodide, but the nitrile moiety reacted as well and the yields of the transformation were considerably lowered.

20. Löwik, D. P. W.; Tisi, L. C.; Murray, J. A. H.; Lowe, C. R. Synthesis 2001, 1780.

21. (a) Marinkova, L.; Mylerova, V. Curr. Org. Chem. 2003, 7, 1279. (b) Wieser, M.; Nagasawa, T. in Stereoselective Biocatalysis; Patel, R. N. Ed.; Marcel Dekker: New York, NY, 2000; p. 461.

22. O’Reilly, C.; Turner, P. D. J. Appl. Microbiol. 2003, 95, 1161.

23. Mateo, C.; Chmura, A.; Rustler, S.; van Rantwijk, F.; Stolz, A.; Sheldon, R.A. Tetrahedron Asymm. 2006, 17, 320.

24. Mukherjee C.; Zhu, D.; Biehl E.R.; Parmar, R.R.; Hua, L. Tetrahedron 2006, 62, 6150.

25. Amess, R.; Baggett, N.; Darby, P. R.; Goode, A. R. Carbohydr. Res. 1990, 205, 225.

26. Franks N. P.; Jenkins, A.; Conti, E.; Lieb, W. R.; Brick, P. Biophys. J. 1998, 75, 2205.

27. Moss, G. W. J.; Franks, N. P.; Lieb, W. R. Proc. Natl. Acad. Sci. USA 1991, 88, 134.

28. Niwa, K.; Ohmiya, Y. Biochem. Biophys. Res. Commun. 2004, 323, 625.

29. Bakhtiarova, A.; Taslimi, P.; Elliman, S. J.; Kosinski, P. A.; Hubbard, B.; Kavana, M.; Kemp, D. M. Biochem. Biophys. Res. Commun. 2006, 351, 481. 